\title{
Interspecies Acetate Transfer Influences the Extent of Anaerobic Benzoate Degradation by Syntrophic Consortia
}

\author{
VEENA WARIKOO,${ }^{1} \dagger$ MICHAEL J. MCINERNEY, ${ }^{1 *}$ JOSEPH A. ROBINSON ${ }^{2}$ \\ AND JOSEPH M. SUFLITA ${ }^{1}$ \\ Department of Botany and Microbiology, University of Oklahoma, Norman, Oklahoma 73019-0245, ${ }^{1}$ \\ and Worldwide Animal Health Product Development, The UpJohn Company, \\ Kalamazoo, Michigan $49001^{2}$
}

Received 8 June 1995/Accepted 13 October 1995

\begin{abstract}
Benzoate degradation by an anaerobic, syntrophic bacterium, strain SB, in coculture with Desulfovibrio sp. strain G-11 reached a threshold value which depended on the amount of acetate added and ranged from about 2.5 to $29.9 \mu \mathrm{M}$. Increasing acetate concentrations also uncompetitively inhibited benzoate degradation. The apparent $V_{\max }$ and apparent $K_{m}$ for benzoate degradation decreased with increasing acetate concentration, but the benzoate degradation capacities $\left(V_{\max } / K_{m}\right)$ of cell suspensions remained comparable. The addition of an acetate-using bacterium to cocultures after the threshold was reached resulted in the degradation of benzoate to below the detection limit. Mathematical simulations showed that the benzoate threshold was not predicted by the inhibitory effect of acetate on benzoate degradation kinetics. With nitrate instead of sulfate as the terminal electron acceptor, no benzoate threshold was observed in the presence of $20 \mathrm{mM}$ acetate even though the kinetics of benzoate degradation were slower with nitrate rather than sulfate as the electron acceptor. When strain SB was grown with Desulfovibrio sp. strain DG2 that had a fourfold-lower $V_{\text {max }}$ for hydrogen use than strain G-11, the $V_{\max }$ for benzoate degradation was 37-fold lower than that of strain SB-G-11 cocultures. The Gibb's free energy for benzoate degradation was less negative in cell suspensions with a threshold than in suspensions without a threshold. These studies showed that the threshold was not a function of the inhibition of benzoate degradation by acetate or the toxicity of the undissociated form of acetate. Rather, a critical or minimal Gibb's free energy may exist where thermodynamic constraints preclude further benzoate degradation.
\end{abstract}

The anaerobic degradation of aromatic compounds involves the concerted action of many microbial species $(18,26,54)$. The initial transformations of aromatic compounds often involve the alteration of substituent groups or ring activation reactions to hydroxylated, carboxylated, or amino derivatives (19). The latter three functional groups and halogens are often removed prior to ring reduction and cleavage. Many times, the result of these transformations is the conversion of diverse aromatic substrates to benzoic acid. Thus, the factors that influence the rate and extent of benzoate degradation may also influence the anaerobic biodegradation of other aromatic compounds.

In methanogenic environments, benzoate is degraded to acetate, $\mathrm{H}_{2}$, and formate by syntrophic bacteria $(18,34,45,49)$. The degradation of benzoate is thermodynamically unfavorable unless the reaction is coupled to the use of hydrogen and/or formate by organisms such as methanogens $(18,30,34)$. We have isolated a new bacterium, strain $\mathrm{SB}$, that degrades benzoate only in coculture with an $\mathrm{H}_{2}$ - or formate-using bacterium such as Desulfovibrio sp. strain G-11 by equation 1 (24):

benzoate ${ }^{-}+6 \mathrm{H}_{2} \mathrm{O} \rightarrow 3$ acetate $^{-}+\mathrm{HCOO}^{-}+2 \mathrm{H}_{2}+3 \mathrm{H}^{+}$

$$
\Delta G^{\mathrm{o} \prime}=69.2 \mathrm{~kJ} / \mathrm{mol}(26)
$$

\footnotetext{
* Corresponding author. Mailing address: Department of Botany and Microbiology, University of Oklahoma, 770 Van Vleet Oval, Norman, OK 73019-0245. Phone: (405) 325-6050. Fax: (405) 325-7619.

$\uparrow$ Present address: Department of Civil Engineering, Stanford University, Stanford, CA 94305-4020.
}

Recently, we showed that SB-G-11 cocultures degrade benzoate to a threshold concentration below which no further benzoate degradation occurs, even after extended incubations (24).

Thresholds for the biodegradation of synthetic and natural organic compounds $(8,12,20,28,33,53)$, for the utilization of inorganic nutrients (12), and for anaerobic hydrogen utilization $(14,29)$ have been reported. The existence of thresholds may explain the persistence of trace levels of many organic compounds in natural waters (25). Little is known about the causes of thresholds. The threshold value for benzoate degradation by the SB-G-11 coculture seemed to be thermodynamically controlled since increased acetate concentrations increased the benzoate threshold value (24). However, there are other possible explanations for the existence of the benzoate threshold. Toxic levels of the undissociated form of acetate have been postulated as the cause of acetate thresholds in pure cultures of acetoclastic methanogens and in acclimatized sludge $(20,21)$. Small increases in the levels of hydrogen and/or formate can inhibit the degradation of ethanol and volatile fatty acids by defined syntrophic consortia and environmental samples $(1,10,17,23,31,36,47,52)$. High concentrations of acetate are also known to inhibit the substrate degradation by syntrophic consortia $(1,6,9,16)$. Further study of the causes of substrate thresholds will be important in understanding the factors that affect the fate of natural and synthetic chemicals in the environment.

We sought to determine whether the benzoate threshold was due to (i) the inhibition of benzoate degradation kinetics by acetate, (ii) the toxicity of the undissociated form of acetate, or 
(iii) the result of thermodynamic limitations. We also examined the effect that different $\mathrm{H}_{2}$ utilization kinetics had on the rate of benzoate degradation by defined syntrophic cocultures.

\section{MATERIALS AND METHODS}

Organisms and growth conditions. A syntrophic benzoate degrader, strain SB, was isolated from sewage sludge (24). Desulfovibrio sp. strain DG2 was kindly provided by J. M. Tiedje, East Lansing, Mich. A basal medium $(24,32)$ with 10 $\mathrm{mM}$ sodium benozate, $30 \mathrm{mM}$ sodium sulfate, $2 \%$ (vol/vol) clarified rumen fluid, and an $80 \% \mathrm{~N}_{2}-20 \% \mathrm{CO}_{2}$ gas phase was used for the growth of strain SB in coculture with either Desulfovibrio sp. strain G-11 or Desulfovibrio sp. strain DG2. Pure cultures of Desulfovibrio sp. strain G-11 and Desulfovibrio sp. strain DG2 were grown in the basal medium with $10 \mathrm{mM}$ sodium sulfate and an $80 \%$ $\mathrm{H}_{2}-20 \% \mathrm{CO}_{2}$ gas phase. Pure cultures of Desulfoarculus baarsii (DSM 2075) were grown in the basal medium with $10 \mathrm{mM}$ each of sodium sulfate and sodium acetate and an $80 \% \mathrm{~N}_{2}-20 \% \mathrm{CO}_{2}$ gas phase.

Methods for the preparation and use of anaerobic media and solutions were essentially those of Bryant (11) as modified by Balch and Wolfe (5). All cultures were incubated at $37^{\circ} \mathrm{C}$. Cultures with hydrogen in the gas phase were incubated on their sides on a rotary shaker, and the headspace of the bottles was repressurized every 2 to 3 days. The purity of cultures was checked routinely by microscopic examination, Gram reaction, and inoculation of thioglycolate broth (Difco Laboratories, Inc., Detroit, Mich.). Growth was monitored by change in $A_{600}$ (35).

Cell suspensions. Cells of the benzoate-degrading cocultures of SB-G-11 and SB-DG2 were concentrated prior to kinetic experiments. All manipulations of cells were done inside an anaerobic chamber, which contained 1 to $5 \%$ of $\mathrm{H}_{2}$ with the balance being $\mathrm{N}_{2}$. About 3 liters of the coculture was grown to the midexponential phase of growth, harvested by centrifugation $(12,000 \times g, 20 \mathrm{~min}$, $\left.4^{\circ} \mathrm{C}\right)$, and washed three times with $50 \mathrm{mM}$ sodium phosphate buffer $(\mathrm{pH} \mathrm{7.5)}$ prior to being resuspended in $100 \mathrm{ml}$ of the basal medium containing 0.2 to 0.3 $\mathrm{mM}$ sodium benzoate and $1 \mathrm{mM}$ sodium sulfate but without vitamins and rumen fluid. The cell suspension was transferred to $160-\mathrm{ml}$ serum bottles which were closed with black rubber stoppers.

Similarly, pure cultures of sulfate reducers were grown to the mid-exponential phase and harvested by centrifugation. Desulfoarculus baarsii cells were washed three times as described above. The final cell pellet was placed on ice in the anaerobic glove box. Cell pellets of Desulfovibrio sp. strains G11 and DG2 were washed twice with anoxic piperazine- $N, N^{\prime}$-bis(2-ethanesulfonic acid) (PIPES) buffer ( $50 \mathrm{mM}, \mathrm{pH} 7.0)$, resuspended in $45 \mathrm{ml}$ of the same buffer, and dispensed into $160-\mathrm{ml}$ serum bottles, which were sealed with black rubber stoppers. The headspace in each bottle was adjusted to $100 \% \mathrm{~N}_{2}(30 \mathrm{kPa})$.

Benzoate kinetics. Kinetic experiments were designed to monitor substrate depletion through the zero-, mixed-, and first-order regions with at least duplicate cell suspensions. Each cell suspension was amended with anoxic solutions of sodium benzoate, sodium sulfate, or sodium nitrate, and 1-ml samples were withdrawn periodically for analysis. To determine the effect of acetate on benzoate degradation, duplicate cell suspensions were amended with sodium benzoate $(200$ to $300 \mu \mathrm{M})$, sodium sulfate $(1 \mathrm{mM})$, and sodium acetate $(0$ to $65 \mathrm{mM})$. Control cell suspensions received $65 \mathrm{mM}$ sodium chloride instead of sodium acetate. Acetate, formate, and hydrogen were quantified when the concentration of benzoate either reached a threshold value or was degraded to below the high-pressure liquid chromatography (HPLC) detection limit $(0.2 \mu \mathrm{M})$.

$\mathbf{H}_{2}$ kinetics. Duplicate cell suspensions of Desulfovibrio sp. strain G-11 or DG2 were amended with an anoxic solution of sodium sulfate to give an initial concentration of $2 \mathrm{mM}$. Hydrogen was added to each serum bottle with a syringe to give an overpressure of 60 to $70 \mathrm{kPa}$. The serum bottles were then incubated at $35^{\circ} \mathrm{C}$ with agitation in an orbital shaker at $200 \mathrm{rpm}$. Autoclaved cell suspensions and buffer without cells served as controls. The gas pressure was measured with a pressure transducer, and changes in transducer output were processed through a switching circuit and digital-analog input-output module to a computer (15). A standard curve relating the amount of $\mathrm{H}_{2}$ added to the serum bottle versus pressure showed that the transducer response was linear up to $110 \mathrm{kPa}$. Also, the electrical output of the pressure transducer was proportional to the gas pressure in the serum bottle $(1 \mathrm{mV} / \mathrm{kPa}) . \mathrm{H}_{2}$ consumption rates were determined by converting the gas pressure measurements into micromoles of $\mathrm{H}_{2}(35)$ as a function of time. The rate of $\mathrm{H}_{2}$ use (in micromoles) was normalized to the amount of total protein present in the bottles. In some serum bottles, the concentration of hydrogen was measured directly with a gas chromatograph equipped with a mercury vapor detector (42) to confirm the accuracy of the pressure transducer data.

Acetate removal experiment. Cell suspensions of strain SB and Desulfovibrio sp. strain G-11 amended with 200 to $300 \mu \mathrm{M}$ benzoate, $1 \mathrm{mM}$ sulfate, and $20 \mathrm{mM}$ acetate were incubated until a benzoate threshold value was reached. The washed cell pellet of Desulfoarculus baarsii was then added to duplicate cell suspensions of the coculture to form a defined triculture. The SB-G-11 cell suspensions not inoculated with Desulfoarculus baarsii served as controls.

Model discrimination. Since the protein concentration did not change during the progress curve experiments (data not shown), mathematical models not linked to growth $(3,4)$ were used to estimate kinetic parameters. A modified second-order model (48) was also tested for the case in which a small increase in biomass occurred during the experiment but was undetected by the protein determination method. The modified second-order model could not be used because no convergence was achieved when this model was fit to various sets of progress curve data. The integrated forms of the Michaelis-Menten model (equation 2) and the first-order model (equation 3) were tested to determine the model that best described the progress curve data:

$$
\begin{gathered}
V_{\max } t=S_{0}-S+K_{m} \ln \left(S_{0} / S\right) \\
S=S_{0} \exp \left(-V_{\max } / K_{m} t\right)
\end{gathered}
$$

$V_{\max }$ is the maximum rate of substrate consumption (in nanomoles minute ${ }^{-1}$ milligram of protein ${ }^{-1}$ ), $K_{m}$ is the half-saturation constant (in micromolar), $S$ is the substrate concentration (in micromolar), $t$ is the time (in minutes), and $S_{0}$ is the initial substrate concentration (in micromolar)

In experiments in which a benzoate threshold concentration was observed, the modified versions of the integrated forms of the Michaelis-Menten model (equation 4) and the first-order model (equation 5) that included threshold terms were used:

$$
\begin{gathered}
V_{\max } t=\left(S_{0}-S\right)+\left(K_{m}+S_{c}\right) \ln \left[\left(S_{c}-S_{\mathrm{o}}\right) /\left(S_{c}-S\right)\right] \\
\left(S_{\mathrm{c}}-S\right)=\left(S_{c}-S_{0}\right) \exp \left[-V_{\max } /\left(K_{m}+S_{c}\right) t\right]
\end{gathered}
$$

In equations 4 and $5, S_{c}$ is the threshold concentration (in micromolar).

The criteria used to assess the goodness-of-fit of the models described above (equations 2 to 5) were (i) the model with the lowest standard error associated with each parameter estimate and (ii) the model that had residual plots with a random distribution of an equal number of positive and negative values about the zero level. On the basis of these criteria, the integrated form of the MichaelisMenten model (equation 2) or its modified version (equation 4) was superior to the other models and was used to estimate the kinetic parameters of benzoate degradation from the progress curve data.

Plots of the sensitivity equations of equations 2 and 4 using data in the first-, mixed-, and zero- order regions showed that the curves generated for the three regions were not multiples of each other (data not shown). Thus, these two equations provided unique estimates of the kinetic parameters.

Inhibition model. Estimates of the Michaelis constants associated with benzoate degradation by Lineweaver-Burk double-reciprocal plots suggested that benzoate degradation was inhibited in the presence of acetate (data not shown). Equations 2 and 4 were modified to account for competitive, noncompetitive, uncompetitive, and mixed types of inhibition (39) to obtain estimates of the inhibition constant $\left(K_{i}\right)$. Initial parameter estimates $\left(V_{\max }\right.$ and $\left.K_{m}\right)$ were obtained with equation 2 and data from experiments in which acetate was not added to the cell suspensions. Equations 2 and 4 modified for the four types of inhibition were each solved for $S$ versus $t$ with different initial acetate concentrations, by using the actual values for $S_{0}$ and $S_{c}$ and the estimates of $V_{\max }, K_{m}$, and $K_{i}$ described above. The substrate decay curves generated from each of the simulations were compared with the respective experimental data to determine which model accurately predicted the mode of acetate inhibition.

Parameter estimation. The least-squares method with the Levenberg-Marquardt algorithm (7) was used for analysis of data from the integrated form of the Michaelis-Menten model (equation 2) and from the modified version of the model (equation 4). All regression analyses were done with a Macintosh Quadra 650 microcomputer (Apple Computer, Inc., Cupertino, Calif.) with Mathcad (MathSoft Inc., Cambridge, Mass.) to perform nonlinear regression analysis.

Analytical methods. Samples were centrifuged at $12,000 \times g$ for $4 \mathrm{~min}$ prior to analysis by HPLC. The concentration of benzoate was determined with an HPLC system equipped with a $\mathrm{C}_{18}$ reverse-phase column $(250 \mathrm{~mm}$ by $4.6 \mathrm{~mm}, 5-\mu \mathrm{m}$ pore size) and a UV detector set at $271 \mathrm{~nm}$. The HPLC was operated at a flow rate of $1.2 \mathrm{ml} / \mathrm{min}$ with a mobile phase of $80 \%$ sodium acetate $(50 \mathrm{mM}, \mathrm{pH} 4.5)$ and $20 \%$ acetonitrile. The detection limit for benzoate was $0.2 \mu \mathrm{M}$. The concentration of acetate was also determined with an HPLC equipped with an ion-exclusion column ( 300 by $7.8 \mathrm{~mm}$ ) and a fixed wavelength UV detector (214 $\mathrm{nm}$ ). A flow rate of $1 \mathrm{ml} / \mathrm{min}$ of $0.03 \mathrm{~N} \mathrm{H}_{2} \mathrm{SO}_{4}$ was used. Identification and quantitation of the eluting compounds were made by comparison with authentic external standards.

The formate concentration was determined spectrophotometrically with a dual-beam instrument operated in the time course mode. The assay is based on measuring the increase in $A_{340}$ due to formate dehydrogenase-catalyzed production of NADH from formate and $\mathrm{NAD}^{+}$. Formate dehydrogenase (from Saccharomyces cerevisiae), $\mathrm{NAD}^{+}$, and NADH solutions were prepared in $50 \mathrm{mM}$ HEPES ( $N$-2-hydroxyethylpiperazine- $N$ '-2-ethanesulfonic acid) buffer at $\mathrm{pH}$ 7.6. Basal medium was used in the reference cuvette as a blank. Medium containing a known amount of formate or without the addition of $\mathrm{NAD}^{+}$served as a control. After the addition of $20 \mu \mathrm{l}$ of $100 \mathrm{mM} \mathrm{NAD}^{+}$solution to the sample, the background absorbance was monitored for 2 to $3 \mathrm{~min}$. The assay was started by the addition of $100 \mu \mathrm{l}$ of a $50-\mathrm{U} / \mathrm{ml}$ formate dehydrogenase solution. The reaction was monitored until no further change in absorbance occurred. A standard curve for $\mathrm{NADH}$ in medium (molar extinction coefficient of $5.33 \times 10^{3}$ ) was generated. The concentration of formate was calculated from the $\Delta A_{340}$ and the $\mathrm{NADH}$ standard curve. The detection limit of the assay was $0.5 \mu \mathrm{M}$. 


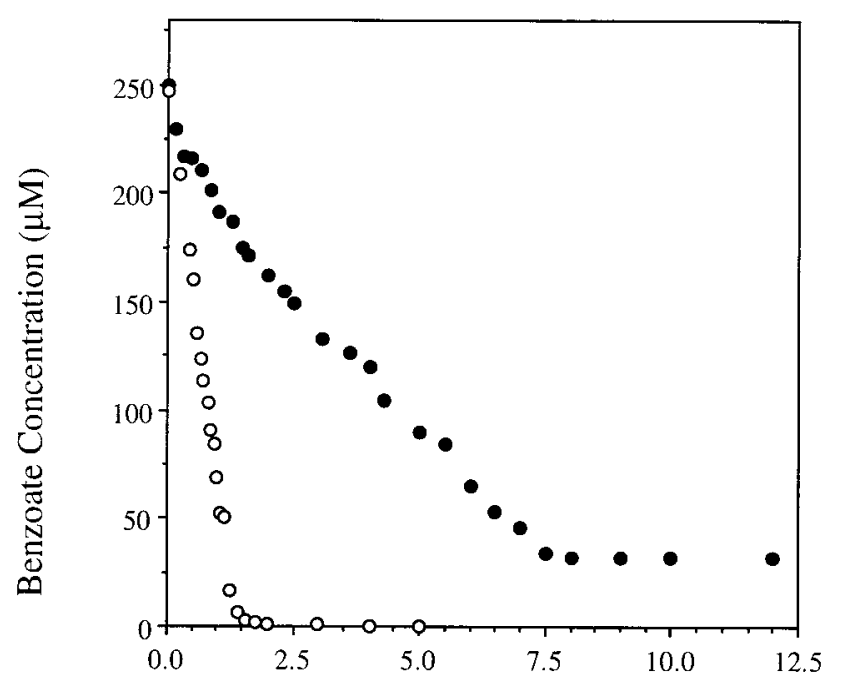

Time (hours)

FIG. 1. Progress curves of benzoate degradation by washed cell suspensions of SB-G-11 cocultures without acetate added $(\bigcirc)$ and with $65 \mathrm{mM}$ acetate $(\bullet)$. The protein concentrations in cell suspensions with and without acetate were 58.7 and $50.9 \mu \mathrm{g} \mathrm{ml}^{-1}$, respectively.

Whole-cell protein was determined with bovine serum albumin as the standard as described previously (29). The samples and the standards were boiled in $0.1 \mathrm{~N}$ $\mathrm{NaOH}$ for 20 min to digest the cells prior to protein determination.

Energetics. At the end of each kinetic experiment, the $\mathrm{pH}$, temperature, and concentrations of benzoate, acetate, formate, and $\mathrm{H}_{2}$ were determined. The change in Gibb's free energy $\left(\Delta G^{\prime}\right)$ for benzoate degradation under nonstandard conditions was calculated by use of the measured concentrations of reactants and products by equation 6 :

$$
\Delta G^{\prime}=\Delta G^{\mathrm{o}^{\prime}}+\mathrm{RT} \ln \frac{\left(\mathrm{CH}_{3} \mathrm{COO}^{-}\right)^{3}\left(\mathrm{H}_{2}\right)^{2}\left(\mathrm{HCOO}^{-}\right)}{\left(\mathrm{C}_{6} \mathrm{H}_{5} \mathrm{COO}^{-}\right)}
$$

where $\left(\mathrm{H}_{2}\right)$ is the $\mathrm{H}_{2}$ partial pressure (in atmospheres [1 $\mathrm{atm}=101.29 \mathrm{kPa}$ ), $\mathrm{R}$ is the gas constant $\left(8.31 \mathrm{~J} \mathrm{~mol}^{-1} \mathrm{~K}^{-1}\right)$, $\mathrm{T}$ is the temperature (in degrees Kelvin), and the values in brackets are the molar concentrations of the respective compounds. The change in standard Gibb's free energy $\left(\Delta G^{\circ \prime}\right)$ for benzoate degradation was calculated from the data in Kaiser and Hanselmann (26).

\section{RESULTS}

Effect of acetate on benzoate decay. Figure 1 shows repre-

TABLE 1. Effect of acetate on the benzoate threshold value and the energetics of benzoate degradation by cell suspensions of strain SB with Desulfovibrio sp. strain G-11 ${ }^{a}$

\begin{tabular}{|c|c|c|c|c|c|}
\hline \multirow[b]{2}{*}{ Addition } & \multicolumn{4}{|c|}{ Final values } & \multirow[b]{2}{*}{$\begin{array}{c}\Delta G^{\prime} \\
\left.(\mathrm{kJ} \mathrm{mol})^{-1}\right)^{b}\end{array}$} \\
\hline & $\begin{array}{l}\text { Benzoate } \\
\text { concn }(\mu \mathrm{M})\end{array}$ & $\begin{array}{l}\text { Acetate } \\
\text { concn } \\
(\mathrm{mM})\end{array}$ & $\begin{array}{l}\text { Hydrogen } \\
\text { pressure } \\
(\mathrm{Pa})\end{array}$ & $\begin{array}{c}\text { Formate } \\
\text { concn } \\
(\mu \mathrm{M})\end{array}$ & \\
\hline \multicolumn{6}{|l|}{ Acetate } \\
\hline $0.0 \mathrm{mM}$ & $<0.2$ & $3.0(0.6)$ & $0.21(0.06)$ & $8.95(0.0)$ & $-42.2(2.8)$ \\
\hline $10.0 \mathrm{mM}$ & $<0.2$ & $13.2(1.5)$ & $0.08(0.09)$ & 7.13 (1.6) & $-36.4(1.9)$ \\
\hline $20.0 \mathrm{mM}$ & $2.3(0.5)$ & $22.0(2.5)$ & $0.40(0.03)$ & $8.07(0.5)$ & $-30.1(2.0)$ \\
\hline $65.0 \mathrm{mM}$ & $29.8(0.5)$ & $65.7(0.2)$ & $0.30(0.10)$ & $7.22(1.5)$ & $-30.5(0.8)$ \\
\hline $\begin{array}{l}\text { Sodium } \\
\text { chloride, } \\
65.0 \mathrm{mM}\end{array}$ & $<0.2$ & $3.1(0.0)$ & $0.22(0.0)$ & $9.1(0.4)$ & $-41.5(0)$ \\
\hline
\end{tabular}

${ }^{a}$ Values are means, with the ranges (differences between the highest and lowest values) given in parentheses.

${ }^{b}$ A value of $0.1 \mu \mathrm{M}$ of benzoate was assumed in the calculations in which the final benzoate concentration reached the detection limit.
TABLE 2. Effect of acetate removal on the benzoate threshold value for the coculture of strain SB and Desulfovibrio sp. strain G-11

\begin{tabular}{|c|c|c|c|c|}
\hline \multirow{2}{*}{$\begin{array}{l}\text { Addition of } \\
\text { D. } \text { baarsii }^{b}\end{array}$} & \multicolumn{2}{|c|}{ Benzoate concn $(\mu \mathrm{M})$} & \multirow{2}{*}{$\begin{array}{l}\text { Final acetate } \\
\text { concn }(\mathrm{mM})\end{array}$} & \multirow{2}{*}{$\begin{array}{l}\text { Final hydrogen } \\
\text { pressure }(\mathrm{Pa})\end{array}$} \\
\hline & $\begin{array}{c}\text { Before } \\
\text { addition }\end{array}$ & $\begin{array}{c}\text { After } \\
\text { addition }\end{array}$ & & \\
\hline No & 78 & $3.7(0.2)$ & $20.3(2.7)$ & $0.32(0.0)$ \\
\hline Yes & $7.1(2.0)$ & $<0.2$ & $9.8(0.4)$ & $0.20(0.1)$ \\
\hline
\end{tabular}

${ }^{a}$ Values are means, with the ranges (differences between the highest and lowest values) given in parentheses.

${ }^{b}$ Cell suspensions contained strain SB and Desulfovibrio sp. strain G-11 and were amended with $20.0 \mathrm{mM}$ acetate and $200 \mu \mathrm{M}$ benzoate. After benzoate was degraded to a threshold concentration, a washed cell suspension of Desulfoarculus baarsii was added to two of the four SB-G-11 cell suspensions.

sentative progress curves for benzoate degradation by cell suspensions of SB-G-11 with and without a sodium acetate amendment. Without the amendment, benzoate was degraded to the detection limit. With $20 \mathrm{mM}$ sodium acetate, the rate of benzoate degradation by the coculture was inhibited and a threshold benzoate concentration was observed. After the threshold was reached, no further benzoate degradation was observed even with extended incubation (14 days).

Experimental manipulation of the acetate concentration (20.0 and $65.7 \mathrm{mM}$ ) resulted in benzoate threshold concentrations of 2.3 and $29.8 \mu \mathrm{M}$, respectively (Table 1). In the cell suspensions amended with $\leq 10 \mathrm{mM}$ sodium acetate or with 65 $\mathrm{mM} \mathrm{NaCl}$, benzoate was degraded to the detection limit (Table $1)$. The $\Delta G^{\prime}$ for benzoate degradation was favorable in all cell suspensions, including those with a benzoate threshold. However, $\Delta G^{\prime}$ for benzoate degradation was less in the cell suspensions without a threshold (Table 1).

When an acetate-using sulfate reducer, Desulfoarculus baarsii, was added to cell suspensions of SB-G-11 that had degraded benzoate to a threshold concentration $(7.1 \mu \mathrm{M})$, decreases in both the acetate and benzoate concentrations were observed (Table 2). In comparable cell suspensions that did not receive Desulfoarculus baarsii, benzoate was degraded to a threshold value of $3.7 \mu \mathrm{M}$ (Table 2).

In cell suspensions amended with different concentrations of sodium acetate, the apparent $V_{\max }$ for benzoate degradation decreased with increasing acetate concentrations (Table 3). However, this decrease in the apparent $V_{\max }$ was offset by a reduction in the apparent $K_{m}$ for benzoate degradation such that the benzoate degradation capacity $\left(V_{\max } / K_{m}\right)$ remained comparable in all cell suspensions (Table 3 ). In cell suspensions amended with $65 \mathrm{mM}$ sodium chloride, the apparent

TABLE 3. Effect of acetate concentration on the kinetic parameters for benzoate degradation by the coculture of strain SB and Desulfovibrio sp. strain G-11

\begin{tabular}{cccc}
\hline Addition & $\begin{array}{c}\text { Apparent } V_{\max } \\
\left(\mathrm{nmol} \mathrm{min} \mathrm{mg}^{-1}\right)^{a}\end{array}$ & $\begin{array}{c}\text { Apparent } K_{m} \\
(\mu \mathrm{M})^{a}\end{array}$ & $\begin{array}{c}V_{\max } / K_{m} \\
\left(\mathrm{~min}^{-1}\right)^{b}\end{array}$ \\
\hline Acetate & & & \\
$0.0 \mathrm{mM}$ & $110.9(5.3)$ & $41.7(3.9)$ & 2.6 \\
$10.0 \mathrm{mM}$ & $50.9(2.8)$ & $20.5(2.8)$ & 2.3 \\
$20.0 \mathrm{mM}$ & $37.7(2.1)$ & $14.2(2.1)$ & 2.4 \\
$65.0 \mathrm{mM}$ & $15.9(1.3)$ & $7.2(0.9)$ & 2.4 \\
Sodium chloride, & $99.8(0.0)$ & $44.6(0.0)$ & 2.2 \\
$65.0 \mathrm{mM}$ & & & \\
\hline
\end{tabular}

${ }^{a}$ Values are means, with the ranges (differences between the highest and lowest values) given in parentheses.

${ }^{b}$ Corrected for $1 \mathrm{mg}$ of protein $\mathrm{ml}^{-1}$. 


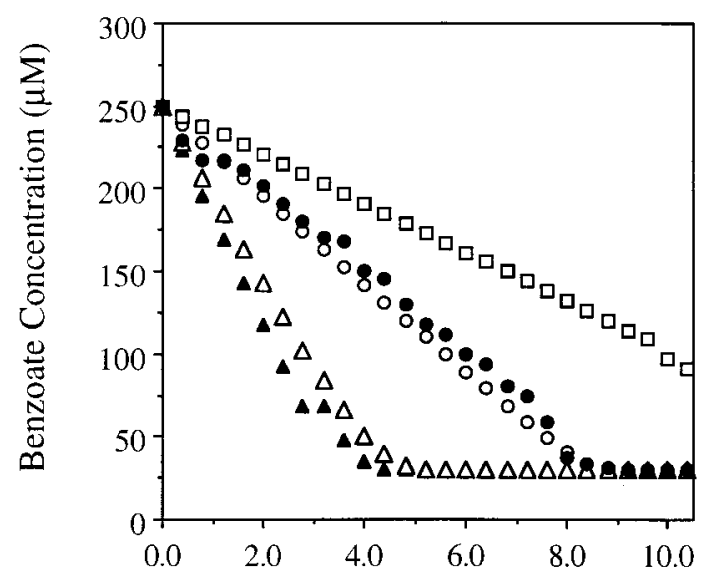

Time (hours)

FIG. 2. Simulation of acetate inhibition of benzoate degradation by the competitive $(\triangle)$, noncompetitive $(\boldsymbol{\Delta})$, uncompetitive $(\bigcirc)$, and mixed $(\square)$ inhibition models with $65 \mathrm{mM}$ acetate. The experimental data obtained with $65 \mathrm{mM}$ acetate (๑) is shown for comparison. The simulated curves were generated with the equations given below and the kinetic parameters determined from experiments without acetate amendment. Equation 4 was modified to include inhibition terms as follows: competitive, $V_{\max } t=\left(S_{0}-S\right)+\left[\left(K_{m}+S_{c}\right)\left(1+1 / K_{i}\right)\right] \ln \left[\left(S_{c}-\right.\right.$ $\left.\left.S_{0}\right) /\left(S_{c}-\mathrm{S}\right)\right]$; noncompetitive, $\left[V_{\max } /\left(1+1 / K_{i}\right)\right] t=\left(S_{0}-S\right)+\left(K_{m}+S_{c}\right) \ln \left[\left(S_{c}\right.\right.$ $\left.\left.-S_{0}\right) /\left(S_{c}-\mathrm{S}\right)\right]$; uncompetitive, $\left[V_{\max } /\left(1+1 / K_{i}\right)\right] t=\left(S_{0}-S\right)+\left[\left(K_{m}+S_{c}\right) /\right.$ $\left.\left(1+1 / K_{i}\right)\right] \ln \left[\left(S_{c}-S_{0}\right) /\left(S_{c}-S\right)\right] ;$ mixed, $\left[V_{\max } /\left(1+1 / K_{i}\right)\right] t=\left(S_{0}-S\right)+\left[\left(K_{m}\right.\right.$ $\left.\left.+S_{c}\right)\left(1+1 / K_{i}\right)\right] \ln \left[\left(S_{c}-S_{0}\right) /\left(S_{c}-S\right)\right]$.

kinetic constants for benzoate degradation were similar to those from cell suspensions without acetate.

Competitive, noncompetitive, uncompetitive, and mixed inhibition models mathematically modified to account for a threshold predicted $K_{i}$ values of $43.2,107,10.0$, and $16.8 \mathrm{mM}$, respectively. Regardless of whether cell suspensions were amended with 10,20 , or $65 \mathrm{mM}$ acetate, the decreases in the apparent $V_{\max }$ and the apparent $K_{m}$ for benzoate degradation were $\geq 50 \%$ (data not shown), indicating that the actual $K_{i}$ for acetate must be $\leq 10 \mathrm{mM}$. Figure 2 compares the actual and simulated benzoate decay curves predicted by the four inhibition models with $65 \mathrm{mM}$ acetate, assuming a $K_{i}$ value of 10 $\mathrm{mM}$. Only the uncompetitive inhibition model accurately simulated the experimental data. A reduction in both the apparent $V_{\max }$ and the apparent $K_{m}$ (Table 3 ) is also consistent with an uncompetitive type of inhibition. Similar results were obtained when simulated and actual benzoate decay curves were compared with initial acetate concentrations of 10 and $20 \mathrm{mM}$ (data not shown). Therefore, it is most likely that acetate functioned as an uncompetitive inhibitor with a $K_{i}$ value of $10.0 \pm 0.6 \mathrm{mM}$. After correcting for acetate inhibition, the $V_{\max }$ and $K_{m}$ estimates for benzoate degradation in the presence of acetate were comparable to those when no acetate was added (data not shown). None of the inhibition models accurately described the course of benzoate decay if they failed to account for the threshold, as illustrated in Fig. 3 for the uncompetitive inhibition model. This was true even if an initial acetate concentration of up to $100 \mathrm{mM}$ was used or when values for $V_{\text {max }}, K_{m}$, and $K_{i}$ were increased or decreased by $50 \%$ of the estimated values (data not shown).

Effect of the terminal electron acceptor on the threshold. Cell suspensions of SB-G-11 amended with $20 \mathrm{mM}$ acetate and the terminal electron acceptor, nitrate, degraded benzoate to below the detection limit (Table 4). In contrast, comparable incubations containing sulfate as the electron acceptor exhibited the expected benzoate threshold (Table 4). Since both

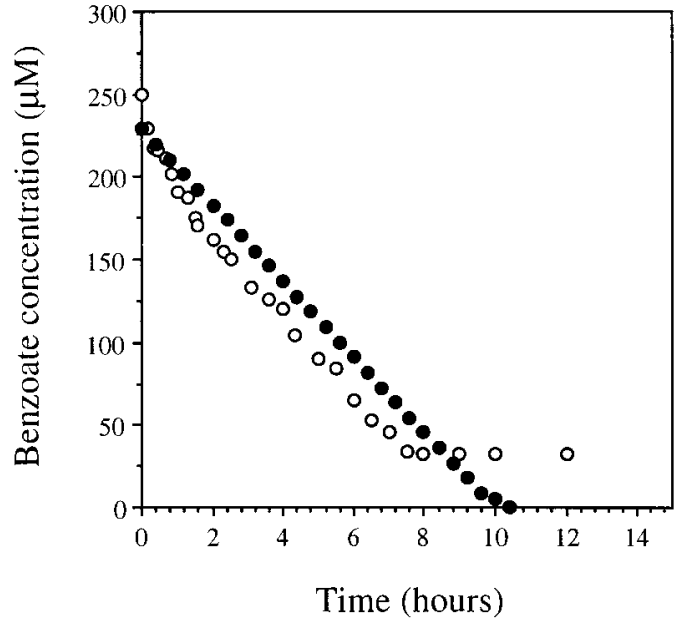

FIG. 3. Simulation study to determine whether acetate inhibition results in a threshold for benzoate degradation. The simulated benzoate degradation curve (0) was generated with equation 4 modified to include a term for uncompetitive inhibition (see legend to Fig. 2) and the values for $V_{\max }, K_{m}, K_{i}$, and $S_{0}$ obtained from experiments with $65 \mathrm{mM}$ acetate. The experimental progress curve $(O)$ obtained with $65 \mathrm{mM}$ acetate is shown for comparison.

suspensions received the same initial amount of sodium acetate, the concentration of the undissociated form of acetate was the same in both cases. However, a benzoate threshold value was observed only when the thermodynamically less favorable electron acceptor, sulfate, was used. This was true even though the $V_{\max }$ was lower and the $K_{m}$ was slightly higher in suspensions containing nitrate than in those containing sulfate as the electron acceptor (Table 4).

Effect of hydrogen utilization capacity on benzoate degradation. The kinetic parameters for $\mathrm{H}_{2}$ use by pure cultures of Desulfovibrio sp. strains G-11 and DG2 were determined by nonlinear regression analysis. The apparent $V_{\max }$ and the apparent $K_{m}$ for $\mathrm{H}_{2}$ utilization were $145 \pm 1.2 \mathrm{nmol} \mathrm{min}^{-1} \mathrm{mg}^{-1}$ and $1.2 \pm 1.2 \mu \mathrm{M}$ for strain $\mathrm{G}-11$ and $34.4 \pm 2.8 \mathrm{nmol} \mathrm{min}{ }^{-1}$ $\mathrm{mg}^{-1}$ and $1.4 \pm 0.4 \mu \mathrm{M}$ for strain $\mathrm{DG}$, respectively. The apparent $V_{\max }$ and the apparent $K_{m}$ for both strains were comparable to values previously reported (40). The $V_{\max } / K_{m}$ of Desulfovibrio sp. strain G-11 was $120.8 \mathrm{~min}^{-1}$, which was five times higher than that of Desulfovibrio sp. strain DG2, 24.5 $\min ^{-1}$.

To determine the effect of hydrogen utilization kinetics on the rate of benzoate degradation, strain SB was grown with either Desulfovibrio sp. strain DG2 or strain G-11. The rate of benzoate degradation decreased 37-fold when strain DG2 was

TABLE 4. Effect of different terminal electron acceptors on the benzoate threshold value and the kinetic parameters for benzoate degradation by the coculture of strain SB and Desulfovibrio sp. strain G-11

\begin{tabular}{ccccccc}
\hline $\begin{array}{c}\text { Concn of ace- } \\
\text { tate added } \\
(\mathrm{mM})\end{array}$ & $\begin{array}{c}\text { Electron } \\
\text { acceptor }\end{array}$ & $\begin{array}{c}\mathrm{A}_{\text {max }}(\mathrm{nmol} \\
\left.\min ^{-1} \mathrm{mg}^{-1}\right)\end{array}$ & $K_{m}(\mu \mathrm{M})$ & $V_{\max ^{-1} / K_{m}}$ & $\begin{array}{c}\text { Final ben- } \\
\left(\mathrm{min}^{-1}\right)^{b}\end{array}$ & $\begin{array}{c}\text { zoate concn } \\
(\mu \mathrm{M})^{a}\end{array}$ \\
\hline 20.0 & Sulfate & $37.7(2.1)$ & $14.2(2.1)$ & 2.4 & $2.3(0.5)$ \\
20.0 & Nitrate & $20.7(0.0)$ & $18.2(0.0)$ & 1.1 & $<0.2$ \\
\hline
\end{tabular}

${ }^{a}$ Values are means, with the ranges (differences between the highest and lowest values) given in parentheses. Data for the condition when sulfate was the terminal electron acceptor are from Table 3.

${ }^{b}$ Corrected to $1 \mathrm{mg}$ of protein $\mathrm{ml}^{-1}$. 
TABLE 5. Effect of different Desulfovibrio strains on the kinetics and energetics of benzoate degradation by strain SB

\begin{tabular}{lrrrrr}
\hline & Acetate & \multicolumn{3}{c}{$\begin{array}{c}\text { Apparent values for benzoate } \\
\text { degradation }\end{array}$} & $\begin{array}{c}\Delta G^{\prime} \\
\text { Strain }^{a}\end{array}$ \\
\cline { 3 - 5 } & $\begin{array}{c}\text { concn } \\
(\mathrm{mM})\end{array}$ & $\begin{array}{c}V_{\text {max }}(\mathrm{nmol} \\
\left.\mathrm{min}^{-1} \mathrm{mg}^{-1}\right)^{b}\end{array}$ & $K_{m}(\mu \mathrm{M})^{b}$ & $\begin{array}{c}V_{\max } / K_{m} \\
\left(\mathrm{~min}^{-1}\right)^{c}\end{array}$ & \\
\hline $\mathrm{kJ}-11$ & 0 & $110.9(5.3)$ & $41.7(3.9)$ & 2.6 & $-42.1(2.8)$ \\
& 10 & $50.9(2.8)$ & $20.5(2.8)$ & 2.5 & $-36.4(1.9)$ \\
DG2 & 0 & $3.0(0.1)$ & $8.7(1.8)$ & 0.3 & $-39.9(2.1)$ \\
& 10 & $0.7(0.3)$ & $1.3(0.2)$ & 0.5 & $-38.9(2.2)$ \\
\hline
\end{tabular}

${ }^{a}$ Data for strain G-11 are from Table 3.

${ }^{b}$ Values are means, with the ranges (differences between the highest and lowest values) given in parentheses.

${ }^{c}$ Corrected for $1 \mathrm{mg}$ of protein $\mathrm{ml}^{-1}$.

the syntrophic partner of strain SB (Table 5). These data showed that the rate of benzoate degradation is controlled by the rate of $\mathrm{H}_{2}$ use by the syntrophic partner. The $\Delta G^{\prime}$ for benzoate degradation in the coculture of SB-DG2 was comparable to the $\Delta G^{\prime}$ in the SB-G-11 coculture (Table 5).

\section{DISCUSSION}

The inhibitory effects of acetate on the kinetics of benzoate degradation by SB-G-11 cocultures could not be adequately explained by a variety of inhibition models unless a term for a benzoate threshold value was included (Fig. 2 and 3). The fact that very high acetate levels (about $80 \mathrm{mM}$ ) inhibit propionate (27) and butyrate $(1,6)$ suggests that thresholds for the degradation of these substrates may also exist. Although Dolfing and Tiedje (16) showed that acetate inhibited the rate of benzoate degradation by a defined syntrophic consortia, a threshold for benzoate degradation was not observed, probably because the rate of benzoate degradation was calculated from the rate of methane production. Thus, it is not known if benzoate was completely degraded. Acetate most likely acted as an uncompetitive inhibitor of benzoate degradation in our cocultures with an apparent $K_{i}$ of $10 \mathrm{mM}$. Dolfing and Tiedje (16) found an apparent $K_{i}$ of $40 \mathrm{mM}$ for acetate inhibition of benzoate degradation by a different syntrophic bacterium in coculture with a methanogen. The $K_{i}$ for acetate inhibition of propionate degradation $(8.3 \mathrm{mM}$ at $\mathrm{pH}$ of 7.0$)$ (21) was very similar to the $K_{i}$ for benzoate degradation reported here.

Several lines of evidence suggest that the threshold for syntrophic benzoate degradation was thermodynamically controlled rather than the result of acetate inhibition or toxicity. Acetate appeared to act as an uncompetitive inhibitor since both the apparent $V_{\max }$ and the apparent $K_{m}$ for benzoate degradation decreased with increasing acetate concentrations (Table 3). This suggests that the threshold may be caused by an inhibition of benzoate degradation kinetics by acetate. When high acetate concentrations are present, the rate of benzoate degradation may be so severely inhibited at low benzoate concentrations that little or no change in benzoate concentration occurs. Simulation studies based on a variety of inhibition models did not predict a benzoate threshold, even when the initial acetate concentration and the values for $V_{\max }, K_{m}$, and $K_{i}$ were varied within reasonable limits. Thus, a kinetic explanation for the benzoate threshold is extremely unlikely.

Toxicity of the undissociated form of acetate cannot be the reason for a benzoate threshold since a threshold was not observed when nitrate substituted for sulfate as an electron acceptor, even though both suspensions had the same initial amendment of acetate (Table 4). The buildup of inhibitory levels of hydrogen is not responsible for a benzoate threshold since hydrogen levels were about $0.4 \mathrm{~Pa}$ (Table 1). Such $\mathrm{H}_{2}$ levels are below that found in other syntrophic associations $(1$, 17, 52). Also, an increase in the $\mathrm{H}_{2}$ partial pressure from 0.25 to $0.85 \mathrm{~Pa}$ did not inhibit the rate of benzoate in a cell suspension of SB-G-11 (data not shown). Similarly, the buildup of formate to inhibitory levels $(10,52)$ can be excluded as a cause of the benzoate threshold since formate concentrations did not differ in cocultures with or without a threshold (Table 1).

Consistent with a thermodynamic explanation, the benzoate threshold value was influenced by the initial acetate concentration (24) (Table 1), the amount of benzoate added (24), and, consequently, the amount of acetate produced. The addition of an acetate-utilizing bacterium to cell suspensions with a benzoate threshold resulted in acetate degradation and further degradation of benzoate (Table 2). This result would be expected if the threshold was thermodynamically controlled since a decrease in the concentration of an end product would tend to pull the reaction in the forward direction. Moreover, no threshold was observed when a thermodynamically more favorable electron acceptor was used, even though the kinetics of benzoate degradation were slower with nitrate than with sulfate as the electron acceptor (Table 4).

Calculations showed that the degradation of benzoate was thermodynamically favorable in cell suspensions exhibiting a threshold, although the $\Delta G^{\prime}$ was more negative in comparable cell suspensions without a threshold (Table 1). It may be that there is a critical change in Gibb's free energy $\left(\Delta G_{c}\right)$ value, above which no further benzoate degradation can occur. A value of about 17 to $23 \mathrm{~kJ}$ has been proposed as the minimum energy quantum needed to conserve energy in a living cell (41, 50). This corresponds to the amount of energy needed to translocate $1 \mathrm{~mol}$ of protons through a fully energized membrane, equivalent to about 0.33 to $0.25 \mathrm{~mol}$ of ATP (41). The $\Delta G^{\prime}$ for benzoate degradation when the threshold was reached is close to the value for the minimum energy quantum (Table 1). The threshold may represent the point at which the free energy change associated with benzoate degradation is not sufficient to allow energy conservation by the cell. A $\Delta G_{c}$ value has been reported for ethanol degradation by a syntrophic coculture of Pelobacter acetylinicus $(43,44)$ and for hydrogen use (13).

An important implication of the present work is that the extent of benzoate degradation can be estimated from thermodynamic considerations. In syntrophic associations, increases in hydrogen and/or formate are often the reason for inhibition of growth and substrate degradation $(1,10,17,23$, $36,47,52)$. Here, we show that an increase in acetate concentration, even when hydrogen and formate levels are low, affects the extent of benzoate degradation in defined syntrophic cultures. If a critical $\Delta G_{c}$ for benzoate degradation exists, then the ratio of acetate to benzoate at which the $\Delta G^{\prime}$ equals $\Delta G_{c}$ can be used to predict the threshold value, assuming that the hydrogen and formate levels are low. When equation 6 is solved for the threshold benzoate concentration at a given acetate concentration by assuming $\Delta G^{\prime}=\Delta G_{c}(-30 \mathrm{~kJ} / \mathrm{mol})$ and by using the hydrogen and formate concentrations of incubations with thresholds (Table 1), the following relationship is obtained:

$$
\left(\text { benzoate }^{-}\right)=0.13\left(\text { acetate }^{-}\right)^{3}
$$

Figure 4 shows that a fairly good agreement exists between the experimental threshold values and the values predicted by the relationship described above. Under methanogenic conditions, where hydrogen concentrations are usually higher $(>1 \mathrm{~Pa})$ 


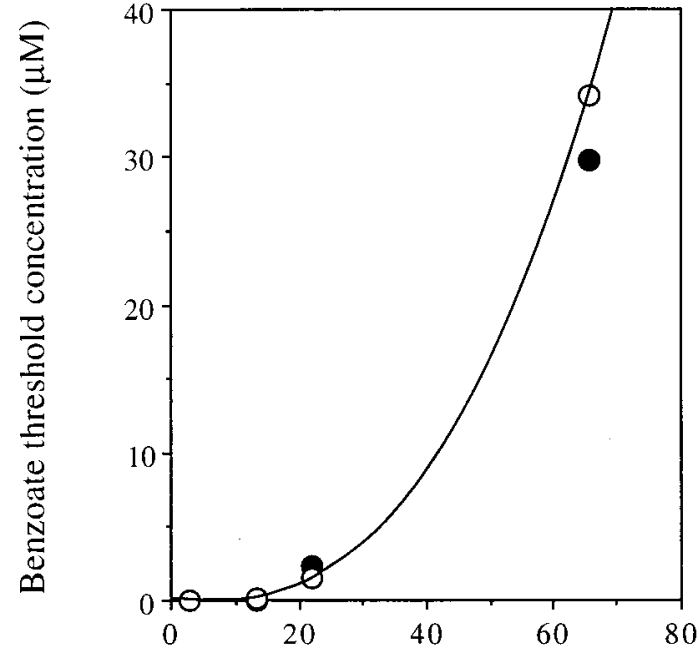

Acetate concentration $(\mu \mathrm{M})$

FIG. 4. Comparison between experimental $(\bullet)$ and predicted $(\bigcirc)$ benzoate threshold values for the coculture of strain SB and Desulfovibrio sp. strain G-11 at different initial acetate concentrations. The predicted benzoate threshold values were calculated with equation 7 and experimentally determined final acetate, formate, and $\mathrm{H}_{2}$ concentrations.

than those under sulfate-reducing conditions, equation 7 would predict a benzoate threshold of about $500 \mu \mathrm{M}$ when the acetate concentration is $22 \mathrm{mM}$.

From a practical standpoint, the relationship described above could be modified to predict the lowest concentration to which an aromatic compound or a volatile fatty acid can be degraded under methanogenic conditions. The influence of acetate on the energetics of benzoate degradation indicates that optimal degradation of benzoate will occur when an active acetate-consuming population exists. The addition of various monocarboxylic acids such as propionate or butyrate dramatically decreased the lag and increased the rate of benzoate metabolism in lake sediments (46) and stimulated the degradation of mono- and di-chlorophenoxyacetates in anaerobic aquifer samples (22), suggesting that stimulating the activity of terminal trophic groups enhances the activity of aromatic degraders. Theile et al. (51) noted that the selection of different syntrophic bacteria and acetate-using methanogens may be the reason for the improved rates of volatile fatty acid degradation in their granules. These studies and the work reported here suggest that both the rate and extent of substrate degradation by syntrophic consortia are controlled by the efficient removal of end products. In particular, we highlight the importance of interspecies acetate transfer.

Cocultures of syntrophic bacteria appear to act as a single organism with the combined metabolic activities of both bacteria. Powell $(37,38)$ developed a theory that explains the tight coupling between the syntrophic partners based on $\mathrm{H}_{2}$ production and consumption kinetics. On the basis of this theory, the specific growth rate of the syntrophic coculture depends largely on the growth rate of the $\mathrm{H}_{2}$-utilizing partner, and this prediction has been confirmed experimentally in several studies (2, $43,44)$. However, it is not clear whether the rate of substrate utilization by the syntrophic bacterium also depends on the $\mathrm{H}_{2}$ utilization kinetics of the $\mathrm{H}_{2}$-using partner. Dwyer et al. (17) found that the rate of butyrate degradation was higher when the syntrophic partner was a sulfate reducer, which had a higher hydrogen utilization capacity $\left(\mu_{\max } / K_{s}\right)$, than in cocultures with a methanogen, which had a lower hydrogen utilization capacity. However, since the electron acceptor differed for these two cocultures, the rate of butyrate degradation could have been influenced by thermodynamic as well as kinetic considerations. Seitz et al. (43) found similar rates of ethanol metabolism in $P$. acetylinicus regardless of whether the hydrogen-using bacterium, a methanogen, a sulfate reducer, or an acetogen was used. We found higher rates of benzoate degradation when SB was grown in coculture with strain G-11 than when it was grown with strain DG-2 (Table 5), which shows that the rate of benzoate degradation by strain SB depended on the hydrogen utilization kinetics of its partner.

Dolfing and Tiedje (16) proposed that it may be possible to grow a syntrophic bacterium in the absence of a hydrogenusing bacterium by interspecies acetate transfer. They based their proposal on the thermodynamic equivalence of acetate and hydrogen plus formate combined with the inhibitory effects of acetate on benzoate degradation at ecologically realistic concentrations. Our findings on the importance of acetate in the rate and extent of substrate degradation by defined syntrophic consortia suggest that such an approach may be feasible.

\section{ACKNOWLEDGMENTS}

We thank N. Q. Wofford for formate determinations.

This work was supported by contract DE-FG05-89ER14003 from the U.S. Department of Energy to M.J.M. and Office of Naval Research grant N00014-93-1-0847 to J.M.S.

\section{REFERENCES}

1. Ahring, B. K., and P. Westermann. 1988. Product inhibition of butyrate metabolism by acetate and hydrogen in a thermophilic coculture. Appl. Environ. Microbiol. 54:2393-2397.

2. Archer, D. B., and G. E. Powell. 1975. Dependence of the specific growth rate of methanogenic mutualistic cocultures on the methanogen. Arch. Microbiol. 141:133-137.

3. Atkins, G. L., and I. A. Nimmo. 1973. The reliability of Michaelis constants and maximum velocities estimated by using the integrated Michaelis-Menten equation. Biochem. J. 135:779-784.

4. Atkins, G. L., and I. A. Nimmo. 1980. Current trends in the estimation of Michaelis-Menten parameters. Anal. Biochem. 104:1-9.

5. Balch, W. E., and R. S. Wolfe. 1976. New approach to the cultivation of methanogenic bacteria: 2-mercaptoethanesulfonic acid (HS-CoM)-dependent growth of Methanobacterium ruminantium in a pressurized atmosphere. Appl. Environ. Microbiol. 32:781-791.

6. Beaty, P. S., and M. J. McInerney. 1989. Effects of organic acid anions on the growth and metabolism of Syntrophomonas wolfei in pure culture and in defined consortia. Appl. Environ. Microbiol. 55:977-983.

7. Beck, J. V., and K. J. Arnold. 1977. Parameter estimation in engineering and science. Wiley-Interscience, New York.

8. Boething, R. S., and M. Alexander. 1979. Effect of concentration of organic chemicals on their biodegradation by natural microbial communities. Appl. Environ. Microbiol. 37:1211-1216.

9. Boone, D. R., and M. P. Bryant. 1980. Propionate-degrading bacterium, Syntrophobacter wolinii sp. nov. gen. nov., from methanogenic ecosystems. Appl. Environ. Microbiol. 40:626-632.

10. Boone, D. R., R. L. Johnson, and Y. Liu. 1989. Diffusion of the interspecies electron carriers $\mathrm{H}_{2}$ and formate in methanogenic ecosystems and its implications in the measurement of $K_{m}$ for $\mathrm{H}_{2}$ and formate uptake. Appl. Environ. Microbiol. 55:1735-1741.

11. Bryant, M. P. 1972. Commentary on the Hungate technique for culture of anaerobic bacteria. Am. J. Clin. Nutr. 25:1324-1328.

12. Button, D. K. 1985. Kinetics of nutrient-limited transport and microbial growth. Microbiol. Rev. 49:270-297.

13. Conrad, R., and B. Wetter. 1990. Influence of temperature on energetics of hydrogen metabolism in homoacetogenic, methanogenic, and other anaerobic bacteria. Arch. Microbiol. 155:94-98.

14. Cord-Ruwisch, R., H. J. Seitz, and R. Conrad. 1988. The capacity of hydrogenotrophic anaerobic bacteria to compete for traces of hydrogen depends on the redox potential of the terminal electron acceptor. Arch. Microbiol. 149: 350-357.

15. DeWeerd, K. A., F. Concannon, and J. M. Suflita. 1991. Relationship be- 
tween hydrogen consumption, dehalogenation, and the reduction of sulfur oxyanions by Desulfomonile tiedjei. Appl. Environ. Microbiol. 57:1929-1934.

16. Dolfing, J., and J. M. Tiedje. 1988. Acetate inhibition of methanogenic syntrophic benzoate degradation. Appl. Environ. Microbiol. 54:1871-1873.

17. Dwyer, D. F., E. Weeg-Aerssens, D. R. Shelton, and J. M. Tiedje. 1988. Bioenergetic conditions of butyrate metabolism by a syntrophic, anaerobic bacterium in coculture with hydrogen-oxidizing methanogenic and sulfidogenic bacteria. Appl. Environ. Microbiol. 54:1354-1359.

18. Ferry, J. G., and R. S. Wolfe. 1976. Anaerobic degradation of benzoate to methane by a microbial consortium. Arch. Microbiol. 107:33-40.

19. Fuchs, G. M., E. S. Mohamed, U. Altenschmidt, J. Roch, A. Lach, R. Brackmann, C. Lockmeyer, and B. Oswald. 1994. Biochemistry of anaerobic biodegradation of aromatic compounds, p. 513-553. In C. Ratledge (ed.), Biochemistry of microbial degradation. Kluwer Academic Publishers, The Netherlands.

20. Fukazaki, S., N. Nishio, and S. Nagai. 1990. Kinetics of the methanogenic fermentation of acetate. Appl. Environ. Microbiol. 56:3158-3163.

21. Fukazaki, S., N. Nishio, M. Shobayashi, and S. Nagai. 1990. Inhibition of the fermentation of propionate to methane by hydrogen, acetate, and propionate. Appl. Environ. Microbiol. 56:719-723.

22. Gibson, S. A., and J. M. Suflita. 1990. Anaerobic biodegradation of 2,4,5, trichlorophenoxyacetic acid in samples from a methanogenic aquifer: stimulation of short-chain organic acids and alcohols. Appl. Environ. Microbiol. 56:1825-1832.

23. Harper, S. R., and F. G. Pohland. 1986. Recent development in hydrogen management during anaerobic biological wastewater treatment. Biotechnol. Bioeng. 28:585-602.

24. Hopkins, B. T., M. J. McInerney, and V. Warikoo. 1994. Evidence for an anaerobic syntrophic benzoate degradation threshold and isolation of the syntrophic benzoate degrader. Appl. Environ. Microbiol. 61:526-530.

25. Jannasch, H. 1967. Growth of marine bacteria at limiting concentrations of organic carbon in seawater. Limnol. Oceanogr. 12:264-271.

26. Kaiser, J.-L., and K. W. Hanselmann. 1982. Fermentative metabolism of substituted monoaromatic compounds by a bacterial community from anaerobic sediments. Arch. Microbiol. 133:384-391.

27. Kasper, H. F., and K. Wuhrmann. 1978. Product inhibition in sludge digestion. Microb. Ecol. 4:241-248.

28. Lovley, D. R. 1985. Minimum threshold for metabolism in methanogenic bacteria. Appl. Environ. Microbiol. 149:1530-1531.

29. Lowry, O. H., N. J. Rosebrough, A. L. Farr, and R. J. Randall. 1951. Protein measurement with the Folin phenol reagent. J. Biol. Chem. 193:265-275.

30. McInerney, M. J., and M. P. Bryant. 1981. Basic principles of bioconversion in anaerobic digestion and methanogenesis, p. 277-296. In S. S. Sofer and O. R. Zoborsky (ed.), Biomass conversions for energy and fuels. Plenum Publishing Corp.., New York.

31. McInerney, M. J., M. P. Bryant, R. B. Hespell, and J. W. Costerton. 1981. Syntrophomonas wolfei gen. nov., sp. nov., an anaerobic, syntrophic, fatty acid-oxidizing bacterium. Appl. Environ. Microbiol. 41:1029-1039.

32. McInerney, M. J., M. P. Bryant, and N. Pfennig. 1979. An anaerobic bacterium that degrades fatty acids in syntrophic association with methanogens. Arch. Microbiol. 122:129-135.

33. Min, H., and S. H. Zinder. 1989. Kinetics of acetate utilization by two thermophilic acetotrophic methanogens: Methanosarcina sp. strain CALS-1 and Methanothrix sp. strain CALS-1. Appl. Environ. Microbiol. 55:488-491.

34. Mountfort, D. O., and M. P. Bryant. 1982. Isolation and characterization of an anaerobic syntrophic benzoate-degrading bacterium from sewage sludge. Arch. Microbiol. 133:249-256.
35. Noggle, J. H. 1989. Physical chemistry, 2nd ed. Scott, Foresman \& Co., Glenview, Ill.

36. Poels, J., P. van Assche, and W. Verstraete. 1985. Influence of $\mathrm{H}_{2}$ stripping on methane production in conventional digestors. Biotechnol. Bioeng. 27: 1692-1698.

37. Powell, G. E. 1984. Equalisation of specific growth rates for syntrophic associations in batch cultures. J. Chem. Technol. Biotechnol. 34B:97-100.

38. Powell, G. E. 1985. Stable coexistence of syntrophic associations in continuous culture. J. Chem. Technol. Biotechnol. 35B:46-50.

39. Roberts, D. V. 1977. Enzyme kinetics. Cambridge University Press, Cambridge.

40. Robinson, J. A., and J. M. Tiedje. 1984. Competition between sulfate-reducing and methanogenic bacteria for $\mathrm{H}_{2}$ under resting and growing conditions. Arch. Microbiol. 137:26-32.

41. Schink, B. 1991. Syntrophism among prokaryotes, p. 276-299. In A. Balows, H. G. Truper, M. Dworkin, W. Harder, and K.-H. Schleifer (ed.), The prokaryotes. A handbook on the biology of bacteria: ecophysiology, isolation, identification, and applications, 2nd ed. Springer-Verlag, New York.

42. Seiler, W., H. Giehl, and P. Roggendorf. 1980. Detection of carbon monoxide and hydrogen by conversion of mercury oxide to mercury vapor. Atmos. Technol. 12:40-45.

43. Seitz, H.-J., B. Schink, and R. Conrad. 1990. Energetics of syntrophic ethanol oxidation in defined chemostat cocultures. 1. Energy requirement for $\mathrm{H}_{2}$ production and $\mathrm{H}_{2}$ oxidation. Arch. Microbiol. 155:82-88.

44. Seitz, H.-J., B. Schink, N. Pfennig, and R. Conrad. 1990. Energetics of syntrophic ethanol oxidation in defined chemostat cocultures. 2. Energy sharing in biomass production. Arch. Microbiol. 155:89-93.

45. Shelton, D. R., and J. M. Tiedje. 1984. Isolation and partial characterization of bacteria in an anaerobic consortium that mineralizes 3-chlorobenzoic acid. Appl. Environ. Microbiol. 48:840-848.

46. Sleat, R., and J. P. Robinson. 1983. Methanogenic degradation of sodium benzoate in produndal sediments from a small eutrophic lake. J. Gen. Microbiol. 129:141-152.

47. Smith, D. P., and P. L. McCarty. 1989. Energetics and the rate effects in the methanogenesis of ethanol and propionate in perturbed CSTR's. Biotechnol. Bioeng. 34:39-47.

48. Suflita, J. M., W. J. Smolenski, and J. A. Robinson. 1987. Alternative nonlinear model for estimating second-order rate coefficient for biodegradation. Appl. Environ. Microbiol. 53:1064-1068.

49. Szewzyk, U., and B. Schink. 1989. Degradation of hydroquinone, gentisate, and benzoate by a fermenting bacterium in pure and defined mixed culture. Arch. Microbiol. 151:541-545.

50. Thauer, R. K., and J. G. Morris. 1984. Metabolism of chemotrophic anaerobes: old views and new aspects. Symp. Soc. Gen. Microbiol. 36:123-168.

51. Theile, J., W.-W. Wu, M. K. Jain, and J. G. Zeikus. 1990. Ecoengineering high rate anaerobic digestion systems: analysis of improved syntrophic biomethanation catalysts. Biotechnol. Bioeng. 35:990-999.

52. Theile, J. H., and J. G. Zeikus. 1988. Control of interspecies flow during anaerobic digestion: significance of formate versus hydrogen transfer during syntrophic methanogenesis in flocs. Appl. Environ. Microbiol. 54:20-29.

53. Westermann, P., B. K. Ahring, and R. A. Mah. 1989. Threshold acetate concentrations for acetate catabolism by acetoclastic methanogenic bacteria. Appl. Environ. Microbiol. 55:514-515.

54. Young, L. Y. 1984. Anaerobic degradation of aromatic compounds, p. 487 583. In D. T. Gibson (ed.), Microbial degradation of organic compounds. Marcel Dekker, New York. 